\title{
A Sequential Approach to the Biodynamic Modeling of a Human Finger
}

\author{
Luka Knez, Janko Slavič, and Miha Boltežar \\ Faculty of Mechanical Engineering, University of Ljubljana, Ljubljana, Slovenia \\ Correspondence should be addressed to Janko Slavič; janko.slavic@fs.uni-lj.si
}

Received 6 December 2016; Accepted 4 July 2017; Published 1 August 2017

Academic Editor: Nuno M. Maia

Copyright (C) 2017 Luka Knez et al. This is an open access article distributed under the Creative Commons Attribution License, which permits unrestricted use, distribution, and reproduction in any medium, provided the original work is properly cited.

\begin{abstract}
In an effort to understand the vibration-induced injuries incurred by manual workers, mechanical models are developed and used to predict the biodynamic responses of human body parts that are exposed to vibration. Researchers have traditionally focused on the arms and hands, but there has been only limited research on finger modeling. To simulate the accurate response of a single finger, a detailed mechanical model based on biodynamic finger measurements is necessary. However, the development of such models may prove difficult using the traditional one-point coupling method; therefore, this study proposes a new approach. A novel device for single-finger measurements is presented and used to expose the finger to a single-axial broadband excitation. The sequentially measured responses of the different finger parts are then used to identify the parameters of a multibody mechanical model of the index finger. Very good agreement between the measured and the simulated data was achieved, and the study also confirmed that the obtained index-finger model is acceptable for further biodynamic studies.
\end{abstract}

\section{Introduction}

Manual workers frequently use a variety of hand tools, for example, chainsaws, grinders, and pneumatic hammers, which lead to vibration being transmitted to their bodies via the hands and arms. Prolonged exposure to handtransmitted vibration can cause different vibration-induced injuries, which are collectively known as hand-arm vibration syndrome (HAVS) [1]. One of the most common conditions is white-fingers syndrome, where the symptoms are localized in the soft tissues and veins of the fingers, as mentioned by Bovenzi [2]. To prevent the occurrence of white-fingers syndrome and help interpret the observed phenomena in epidemiological and physiological studies, the complex biodynamic responses of the fingers are measured and modeled $[3,4]$.

The most extensively used method for dynamic-response measurements of the hand is the biodynamic-response method, which is summarized by Dong et al. in $[3,5]$ and was introduced as an alternative to the ISO 10819 standard [6]. A comparison was made between the standard and biodynamic methods in [7] and the biodynamic method was found to be practical since it removes the need for the standard handheld palm adapter. The biodynamic-response method originally measured the dynamic responses of the palm only $[5,8]$, but it was recently upgraded to finger-response measurements [9-11] as well. The biodynamic-response method is based on the biodynamic parameters, for example, apparent mass, mechanical impedance, and apparent stiffness, which are derived from measurements made on a device subjected to vibration. Broadband random or sine excitation is used to simulate hand-tool excitations and simultaneous measurements of the dynamic motion and forces on the palm or fingers at the hand-device interface are required to calculate the biodynamic parameters. In an effort to produce comparable results with other biodynamic research, the operator's posture and the pushing or gripping forces are also monitored during the tests, as recommended by Adewusi et al. [12] and Aldien et al. [13]. The sizes of the pushing and gripping forces were also chosen based on the research of Marcotte et al. [14].

Using the measured biodynamic responses of the palm and the fingers, various mechanical models of the hand have been developed [3]. However, until recently, only the biodynamic response of the entire hand has been measured; 
therefore, researchers have been developing whole hand-arm models with limited focus on the hand's subparts (see reviews $[15,16])$. As the biodynamic-response method improved, however, Adewusi et al. [17] and Dong et al. [18, 19] started focusing on separate palm and fingers models, which were also upgraded for all three orthogonal directions [20]. The fingers in these models are represented only simply: only one or two lumped-mass elements are used for all five fingers. To calculate detailed finger responses, researchers have developed physical models; for example, Pawluk and Howe [21] used a lumped element to simulate the dynamic contact of a finger pad with a flat surface. Jindrich et al. [22] applied a modified lumped element to simulate the force-displacement characteristics of the fingertip. Srinivasan [23] proposed a "waterbed" model where the fingertip is represented by an incompressible fluid and is enclosed in an elastic membrane and Serina et al. [24] proposed an improved model using a nonlinear elastic skin membrane and the finite-deformation theory. Given the improvements in the biodynamic-response measurements and physical modeling and by taking account of the finger's anatomical structure, a more detailed model of the finger needs to be developed.

Besides lumped-mass elements, finite-element models are also used for finger modeling (see, e.g., $[25,26])$. These models focus on specific details of the finger, for example, stress/strain distributions in the fingertip, modeling of the soft tissue, bone, and nail, and the tactile discrimination test, and not on the biodynamic response of all the fingers. A major downside of finite-element finger models is that developing a sufficiently experimentally validated FE model is a challenging research task and FE modeling is also both expensive and time-consuming [20].

In this study, it is hypothesized that a lumped-parameter model based on the multipoint coupling approach may be sufficient to derive a representative biodynamic response of the finger. A sequential approach to detailed finger modeling is proposed and several model configurations are considered, each representing different phalanxes of the index finger. The experimental data used in the models was derived in the form of the apparent mass using a purpose-built measuring device. The device was developed based on our previous research $[9,10]$ as well as the current state of the art from other researchers [11,27,28]. The parameters for each of the models were obtained by data fitting and the search was conducted sequentially: the distal phalanx parameters were derived first, followed by the middle and proximal phalanx parameters. The combined parameters resulted in the biodynamic response of the entire finger.

\section{Theory and Modeling}

2.1. Biodynamic Theory. An elementary overview of the biodynamic theory is presented here. The theory is used to derive both the modeled and the measured biodynamic responses of the index finger, researched in this study. An in-depth analysis and explanation (based on the whole hand-arm system) can be found in $[1,5]$.

The biodynamic response of a dynamical system can be characterized by the apparent mass (AM), the mechanical impedance (MI), and the apparent stiffness (AS), all of which reflect different physical characteristics of the same mechanical system and can be derived from each other. The AM was chosen for this study since it emphasizes the low-frequency components of the biodynamic response [11], which are typically found in the fingers' dynamic response. Generally, the AM is defined as [5]

$$
\mathrm{AM}=\frac{\widetilde{F}}{\widetilde{A}}
$$

where $\widetilde{F}$ is the dynamic force and $\widetilde{A}$ is the dynamic acceleration at the interface between the finger and the measuring device. Both parameters must be measured simultaneously and in the direction of excitation.

In the frequency domain, the AM defined in (1) is obtained as

$$
\operatorname{AM}(\mathrm{j} \omega)=\frac{G_{f a}(\mathrm{j} \omega)}{G_{a a}(\mathrm{j} \omega)},
$$

where $G_{f a}$ is the cross-spectrum density of the force and the acceleration and $G_{a a}$ is the autospectrum density of the acceleration. The results are complex numbers, comprising both the real and the imaginary components.

However, in practice, it is easier to estimate the AM as shown by Stein et al. [29]:

$$
\mathrm{AM}(\mathrm{j} \omega)=\frac{F(\mathrm{j} \omega)}{a(\mathrm{j} \omega)},
$$

where the required excitation acceleration $a(\mathrm{j} \omega)$ is usually generated with a shaker and the resulting force $F(\mathrm{j} \omega)$ is measured at the interface between the finger and the measuring device.

Every sensor used in the measurement has a certain amount of mass; therefore, the measured force of the finger $F(\mathrm{j} \omega)$ is actually a combination of the finger's biodynamic force and the inertial force of the measuring device. To calculate the exact $\mathrm{AM}$ of the finger $\mathrm{AM}_{\mathrm{F}}$, it is therefore necessary to deduct the influence of the measuring device $\mathrm{AM}_{\mathrm{Dev}}$ from the total (finger plus device) $\mathrm{AM} \mathrm{AM}_{\mathrm{TF}}$ :

$$
\operatorname{AM}_{\mathrm{F}}(\mathrm{j} \omega)=\mathrm{AM}_{\mathrm{TF}}(\mathrm{j} \omega)-\mathrm{AM}_{\mathrm{Dev}}(\mathrm{j} \omega) .
$$

$\mathrm{AM}_{\text {Dev }}$ in (4) can be calculated from the data obtained on an empty measuring device, where the dynamic force is purely the result of the measuring device's mass.

2.2. Finger Model Formulations. This study introduces a sequential modeling principle to systematically derive a multibody mechanical model of the finger. First, the joints connecting the different finger phalanxes were modeled using a simplified rotational and translational mechanical joint. An example joint between bodies $i$ and $j$, which is used in all the model configurations in this study, can be seen in Figure 1. The joint consists of rotational stiffness and damping denoted as $k r_{i j}$ and $c r_{i j}$ as well as the $Y$-direction translational stiffness $k_{i j}$ and damping $c_{i j}$. The $X$-direction 


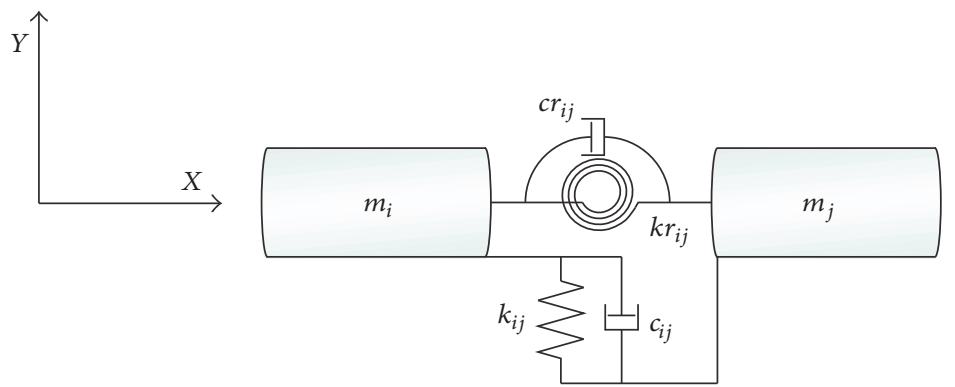

FIGURE 1: The simplified rotational and translational mechanical joint used to represent the interphalangeal joints of the finger.

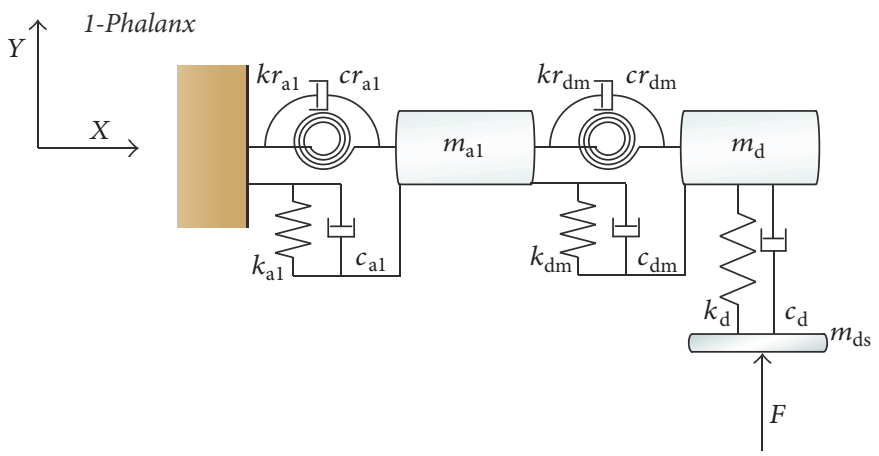

FIGURE 2: The model configuration used for the distal finger phalanx (denoted as 1-Phalanx).

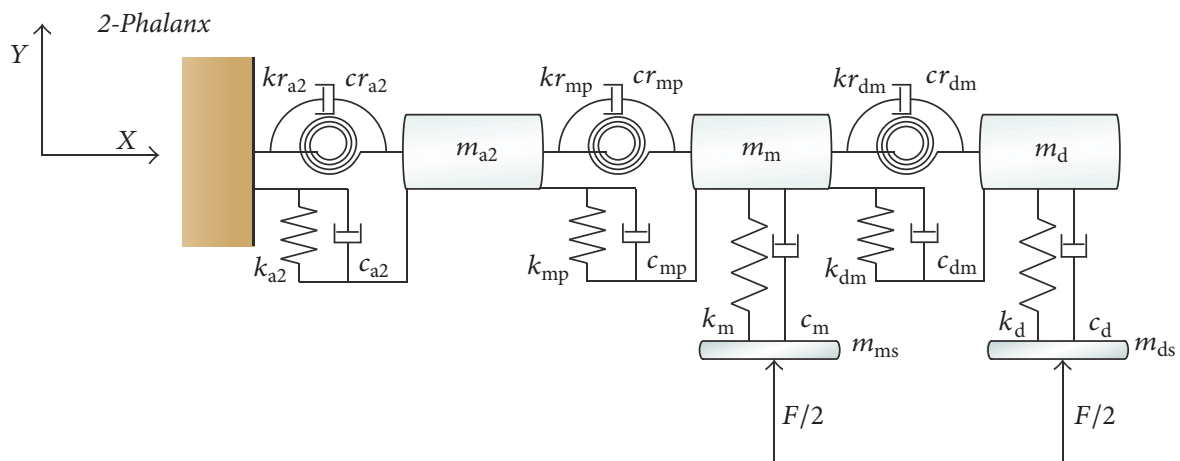

FIGURE 3: The model configuration used for the distal and middle finger phalanxes (denoted as 2-Phalanx).

stiffness and damping are neglected due to the assumption of small rotations and also the negligible movement of the models in the $X$-direction.

The model configurations used in this study are shown in Figures 2-4 and represent different phalanxes of the index finger. They were denoted based on the number of phalanxes in each respective model: 1-Phalanx, 2-Phalanx, and 3-Phalanx.

In the 1-Phalanx model, the mass $m_{\mathrm{d}}$ represents the distal phalanx bone and muscle-tissue mass. The skin of the phalanx is denoted as $m_{\mathrm{ds}}$ and is in direct contact with a vibrating surface. This is simulated by applying an external force $F$. The tissue located between the bone and the skin is represented as the translational stiffness $k_{\mathrm{d}}$ and the damping $c_{\mathrm{d}}$. The simplified joint described above is used to model the joint between the distal and middle phalanxes, where $k r_{\mathrm{dm}}$ represents the rotational stiffness, $c r_{\mathrm{dm}}$ the rotational damping, $k_{\mathrm{dm}}$ the translational stiffness, and $c_{\mathrm{dm}}$ the translational damping in the $Y$-direction. It is also hypothesized that the AM of the distal phalanx is partly affected by the middle phalanx and possibly more of the finger (this will become more evident during the modeling-measurement comparison later on). The contribution to the AM by the rest of the finger is modeled using the mass $m_{\mathrm{a} 1}$ (where "a" denotes the term "additional") and a joint with rotational and translational stiffness and damping $\left(k r_{\mathrm{a} 1}, k_{\mathrm{a} 1}, c r_{\mathrm{a} 1}\right.$, and $\left.c_{\mathrm{a} 1}\right)$.

The 2-Phalanx and 3-Phalanx models follow the same modeling logic. The letter " $\mathrm{m}$ " denotes the middle phalanx and "p" the proximal phalanx, which is then connected to the hand via the interphalangeal joint. The skin $\left(m_{\mathrm{ms}}, m_{\mathrm{ps}}\right)$ 


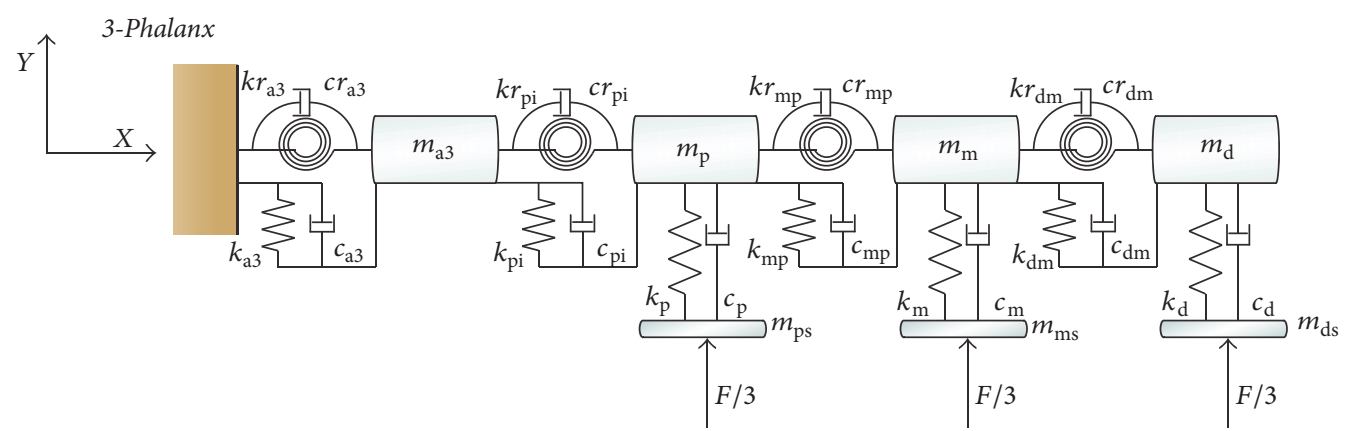

FIgURE 4: The model configuration used for the distal, middle, and proximal finger phalanxes (denoted as 3-Phalanx).

is again in direct contact with the vibrating surface and this is simulated with an external force $F$. The distribution of the external force exerted on the surface is considered uniform, therefore $F / 2$ for the 2-Phalanx and $F / 3$ for the 3-Phalanx model. The tissue properties between the bones and the skin are modeled using the translational stiffness $\left(k_{\mathrm{m}}, k_{\mathrm{p}}\right)$ and damping $\left(c_{\mathrm{m}}, c_{\mathrm{p}}\right)$. The interphalangeal joints are represented by the rotational and translational stiffness $\left(k r_{\mathrm{mp}}, k_{\mathrm{mp}}, k r_{\mathrm{pi}}\right.$, and $\left.k_{\mathrm{pi}}\right)$ and the damping $\left(c r_{\mathrm{mp}}, c_{\mathrm{mp}}, c r_{\mathrm{pi}}\right.$, and $c_{\mathrm{pi}}$ ). The contribution or addition to the measured AM is denoted by $m_{\mathrm{a} 2}, m_{\mathrm{a} 3}, k r_{\mathrm{a} 2}, k_{\mathrm{a} 2}, k r_{\mathrm{a} 3}, k_{\mathrm{a} 3}, c r_{\mathrm{a} 2}, c_{\mathrm{a} 2}, c r_{\mathrm{a} 3}$, and $c_{\mathrm{a} 3}$ for the 2-Phalanx and 3-Phalanx models accordingly.

2.3. Equations of Motion and Apparent Mass of the Models. The equations of motion for the models presented in Section 2.2 are derived using the multibody dynamics approach as defined by Shabana [30]. The advantage of this approach is that the models are easy to upgrade and the equations of motion are ready for a direct computer implementation.

The motion of a general rigid body $i$ in a multibody system can be expressed as

$$
\mathbf{M}^{i} \ddot{\mathbf{q}}^{i}=\mathbf{Q}_{e}^{i}+\mathbf{Q}_{c}^{i},
$$

where $\mathbf{M}^{i}$ is the mass matrix of the rigid body $i, \ddot{\mathbf{q}}^{i}=$ $\left[\begin{array}{ll}\ddot{\mathbf{R}}^{i T} & \ddot{\varphi}^{i}\end{array}\right]^{T}$ is the acceleration vector, $\mathbf{Q}_{e}^{i}$ is the vector of generalized external forces, and $\mathbf{Q}_{c}^{i}$ is the vector of generalized constraint forces acting on the body $i$. For a system of $n$ interconnected bodies, (5) can be used to develop the system's equations of motion:

$$
\mathbf{M} \ddot{\mathbf{q}}=\mathbf{Q}_{e}+\mathbf{Q}_{c},
$$

where $\mathbf{M}$ is the mass matrix, $\ddot{\mathbf{q}}$ is the vector of generalized acceleration, $\mathbf{Q}_{e}$ is the vector of external forces, and $\mathbf{Q}_{c}$ is the vector of constraint forces.

Due to the model's configurations and the use of rotational and translational joints, as presented in Figure 1, (6) can be simplified as

$$
\mathbf{M} \ddot{\mathbf{q}}=\mathbf{Q}_{e}
$$

and rewritten in the following form:

$$
\mathbf{M} \cdot \ddot{\mathbf{q}}(t)+\mathbf{C} \cdot \dot{\mathbf{q}}(t)+\mathbf{K} \cdot \mathbf{q}(t)=\mathbf{F},
$$

where $\mathbf{C}$ is the damping matrix, $\mathbf{K}$ is the stiffness matrix, $\mathbf{F}$ is the force vector, and $\dot{\mathbf{q}}$ and $\mathbf{q}$ are the velocity and displacement response vectors, respectively. Equation (8) generally produces a coupled system of equations.

To derive a system of uncoupled equations, (8) is simplified as proposed by Adewusi et al. [17]. Small angles are assumed and the second-order terms of motions, which are a product of the rotational and translational motions, are neglected. The simplified system of equations can now be derived and, for example, the 1-Phalanx model equations can be written as follows:

$$
\mathbf{M}\left\{\begin{array}{c}
\ddot{y}_{\mathrm{a} 1} \\
\ddot{\varphi}_{\mathrm{a} 1} \\
\ddot{y}_{\mathrm{d}} \\
\ddot{\varphi}_{\mathrm{d}} \\
\ddot{y}_{\mathrm{ds}}
\end{array}\right\}+\mathbf{C}\left\{\begin{array}{c}
\dot{y}_{\mathrm{a} 1} \\
\dot{\varphi}_{\mathrm{a} 1} \\
\dot{y}_{\mathrm{d}} \\
\dot{\varphi}_{\mathrm{d}} \\
\dot{y}_{\mathrm{ds}}
\end{array}\right\}+\mathbf{K}\left\{\begin{array}{c}
y_{\mathrm{a} 1} \\
\varphi_{\mathrm{a} 1} \\
y_{\mathrm{d}} \\
\varphi_{\mathrm{d}} \\
y_{\mathrm{ds}}
\end{array}\right\}=\left\{\begin{array}{c}
0 \\
0 \\
0 \\
0 \\
F(t)
\end{array}\right\},
$$

where

$$
\mathbf{M}=\left[\begin{array}{ccccc}
m_{\mathrm{a} 1} & 0 & 0 & 0 & 0 \\
0 & J_{\mathrm{a} 1} & 0 & 0 & 0 \\
0 & 0 & m_{\mathrm{d}} & 0 & 0 \\
0 & 0 & 0 & J_{\mathrm{d}} & 0 \\
0 & 0 & 0 & 0 & m_{\mathrm{ds}}
\end{array}\right]
$$




$$
\begin{array}{r}
\mathbf{C}=\left[\begin{array}{ccccc}
c_{\mathrm{a} 1}+c_{\mathrm{dm}} & \left(c_{\mathrm{dm}}-c_{\mathrm{a} 1}\right) \frac{l_{\mathrm{a} 1}}{2} & -c_{\mathrm{dm}} & c_{\mathrm{dm}} \frac{l_{\mathrm{d}}}{2} & 0 \\
\left(c_{\mathrm{dm}}-c_{\mathrm{a} 1}\right) \frac{l_{\mathrm{a} 1}}{2} & c r_{\mathrm{a} 1}+c r_{\mathrm{dm}}+\left(c_{\mathrm{a} 1}+c_{\mathrm{dm}}\right) \frac{l_{\mathrm{a} 1}^{2}}{4} & -c_{\mathrm{dm}} \frac{l_{\mathrm{a} 1}}{2} & -c r_{\mathrm{dm}}+c_{\mathrm{dm}} \frac{l_{\mathrm{a} 1} l_{\mathrm{d}}}{4} & 0 \\
-c_{\mathrm{dm}} & -c_{\mathrm{dm}} \frac{l_{\mathrm{a} 1}}{2} & c_{\mathrm{dm}}+c_{\mathrm{d}} & -c_{\mathrm{dm}} \frac{l_{\mathrm{d}}}{2} & -c_{\mathrm{d}} \\
c_{\mathrm{dm}} \frac{l_{\mathrm{d}}}{2} & -c r_{\mathrm{dm}}+c_{\mathrm{dm}} \frac{l_{\mathrm{a} 1} l_{\mathrm{d}}}{4} & -c_{\mathrm{dm}} \frac{l_{\mathrm{d}}}{2} & c r_{\mathrm{dm}}+c_{\mathrm{dm}} \frac{l_{\mathrm{d}}^{2}}{4} & 0 \\
0 & 0 & -c_{\mathrm{d}} & 0 & c_{\mathrm{d}}
\end{array}\right], \\
\mathbf{K}=\left[\begin{array}{ccccc}
k_{\mathrm{a} 1}+k_{\mathrm{dm}} & \left(k_{\mathrm{dm}}-k_{\mathrm{a} 1}\right) \frac{l_{\mathrm{a} 1}}{2} & -k_{\mathrm{dm}} & k_{\mathrm{dm}} \frac{l_{\mathrm{d}}}{2} & 0 \\
\left(k_{\mathrm{dm}}-k_{\mathrm{a} 1}\right) \frac{l_{\mathrm{a} 1}}{2} & k r_{\mathrm{a} 1}+k r_{\mathrm{dm}}+\left(k_{\mathrm{a} 1}+k_{\mathrm{dm}}\right) \frac{l_{\mathrm{a} 1}^{2}}{4} & -k_{\mathrm{dm}} \frac{l_{\mathrm{a} 1}}{2} & -k r_{\mathrm{dm}}+k_{\mathrm{dm}} \frac{l_{\mathrm{a} 1} l_{\mathrm{d}}}{4} & 0 \\
-k_{\mathrm{dm}} & -k_{\mathrm{dm}} \frac{l_{\mathrm{a} 1}}{2} & k_{\mathrm{dm}}+k_{\mathrm{d}} & -k_{\mathrm{dm}} \frac{l_{\mathrm{d}}}{2} & -k_{\mathrm{d}} \\
k_{\mathrm{dm}} \frac{l_{\mathrm{d}}}{2} & -k r_{\mathrm{dm}}+k_{\mathrm{dm}} \frac{l_{\mathrm{a} 1} l_{\mathrm{d}}}{4} & -k_{\mathrm{dm}} \frac{l_{\mathrm{d}}}{2} & k r_{\mathrm{dm}}+k_{\mathrm{dm}} \frac{l_{\mathrm{d}}^{2}}{4} & 0 \\
0 & 0 & -k_{\mathrm{d}} & 0 & k_{\mathrm{d}}
\end{array}\right] .
\end{array}
$$

The systems of equations for the 2-Phalanx and 3-Phalanx models are also derived using the same procedure. Assuming harmonic excitation for the measuring device,

$$
y(t)=Y_{\text {Dev }} \mathrm{e}^{\mathrm{j} \omega t},
$$

and also harmonic solutions,

$$
\begin{aligned}
& q(t)=Q \mathrm{e}^{\mathrm{j} \omega t}, \\
& \dot{q}(t)=Q \mathrm{j} \omega \mathrm{e}^{\mathrm{j} \omega t}, \\
& \ddot{q}(t)=-Q \omega^{2} \mathrm{e}^{\mathrm{j} \omega t},
\end{aligned}
$$

the equations of motion (e.g., (9) for 1-Phalanx) can now be expressed in the frequency domain and solved for the frequency-response functions of the models:

$$
Q(j \omega)=\left[-\omega^{2} \mathbf{M}+\mathrm{j} \omega \mathbf{C}+\mathbf{K}\right]^{-1} F(\mathrm{j} \omega),
$$

where $\omega$ corresponds to the angular excitation frequency and $\mathrm{j}=\sqrt{-1}$. The frequency-response vectors obtained from (13) are

$$
Q_{1-P h a}(j \omega)=\left[Y_{\mathrm{a} 1}, \theta_{\mathrm{a} 1}, Y_{\mathrm{d}}, \theta_{\mathrm{d}}, Y_{\mathrm{ds}}\right]
$$

for the 1-Phalanx model,

$$
\mathrm{Q}_{2-\mathrm{Pha}}(\mathrm{j} \omega)=\left[Y_{\mathrm{a} 2}, \theta_{\mathrm{a} 2}, Y_{\mathrm{m}}, \theta_{\mathrm{m}}, Y_{\mathrm{ms}}, Y_{\mathrm{d}}, \theta_{\mathrm{d}}, Y_{\mathrm{ds}}\right]
$$

for the 2-Phalanx model, and

$$
\begin{aligned}
& Q_{3-\text { Pha }}(j \omega) \\
& \quad=\left[Y_{\mathrm{a} 3}, \theta_{\mathrm{a} 3}, Y_{\mathrm{p}}, \theta_{\mathrm{p}}, Y_{\mathrm{ps}}, Y_{\mathrm{m}}, \theta_{\mathrm{m}}, Y_{\mathrm{ms}}, Y_{\mathrm{d}}, \theta_{\mathrm{d}}, Y_{\mathrm{ds}}\right]
\end{aligned}
$$

for the 3-Phalanx model.
The AM of the models can now be obtained from the finger-handle interface:

$$
\operatorname{AM}(j \omega)=\sum_{i=1}^{n} \frac{(1 / i) F(j \omega)}{-\omega^{2} Q_{i}(j \omega)},
$$

where $n$ is the number of bodies in the model that are directly excited via an external force and is dependent on the model's configuration. Specifically,

$$
\begin{aligned}
& \operatorname{AM}_{1-\text { Pha }}(\mathrm{j} \omega) \\
& =\frac{-\omega^{2} Y_{\text {Dev }} m_{\mathrm{ds}}+\left(k_{\mathrm{d}}+c_{\mathrm{d}}\right)\left(Y_{\mathrm{Dev}}-Y_{\mathrm{ds}}\right)}{-\omega^{2} Y_{\text {Dev }}}
\end{aligned}
$$

for the 1-Phalanx model,

$$
\begin{aligned}
\operatorname{AM}_{2-\text { Pha }}(\mathrm{j} \omega) & \frac{-\omega^{2} Y_{\text {Dev }} m_{\mathrm{ds}}+\left(k_{\mathrm{d}}+c_{\mathrm{d}} \mathrm{j}\right)\left(Y_{\text {Dev }}-Y_{\mathrm{ds}}\right)}{-\omega^{2} Y_{\text {Dev }}} \\
& +\frac{-\omega^{2} Y_{\text {Dev }} m_{\mathrm{ms}}+\left(k_{\mathrm{m}}+c_{\mathrm{m}} \mathrm{j}\right)\left(Y_{\text {Dev }}-Y_{\mathrm{ms}}\right)}{-\omega^{2} Y_{\text {Dev }}}
\end{aligned}
$$

for the 2-Phalanx model, and

$$
\begin{aligned}
\mathrm{AM}_{3-\text { Pha }}(\mathrm{j} \omega) & \frac{-\omega^{2} Y_{\text {Dev }} m_{\mathrm{ds}}+\left(k_{\mathrm{d}}+c_{\mathrm{d}} \mathrm{j}\right)\left(Y_{\text {Dev }}-Y_{\mathrm{ds}}\right)}{-\omega^{2} Y_{\text {Dev }}} \\
& +\frac{-\omega^{2} Y_{\text {Dev }} m_{\mathrm{ms}}+\left(k_{\mathrm{m}}+c_{\mathrm{m}} \mathrm{j}\right)\left(Y_{\text {Dev }}-Y_{\mathrm{ms}}\right)}{-\omega^{2} Y_{\text {Dev }}} \\
& +\frac{-\omega^{2} Y_{\text {Dev }} m_{\mathrm{ps}}+\left(k_{\mathrm{p}}+c_{\mathrm{p}} \mathrm{j}\right)\left(Y_{\text {Dev }}-Y_{\mathrm{ps}}\right)}{-\omega^{2} Y_{\text {Dev }}}
\end{aligned}
$$

for the 3-Phalanx model. 


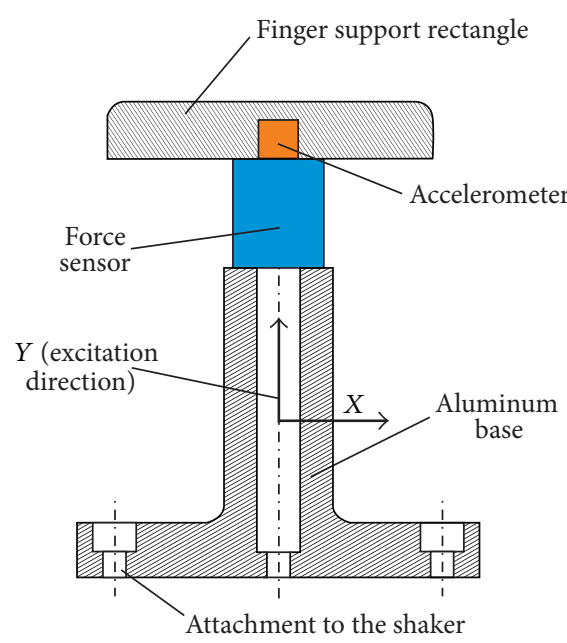

(a)

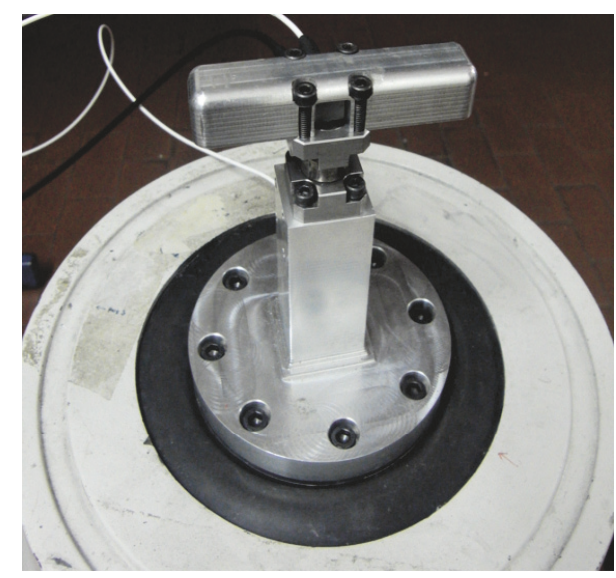

(b)

FIgURE 5: The measuring device: (a) a sketch of the device; (b) a photograph of the device.

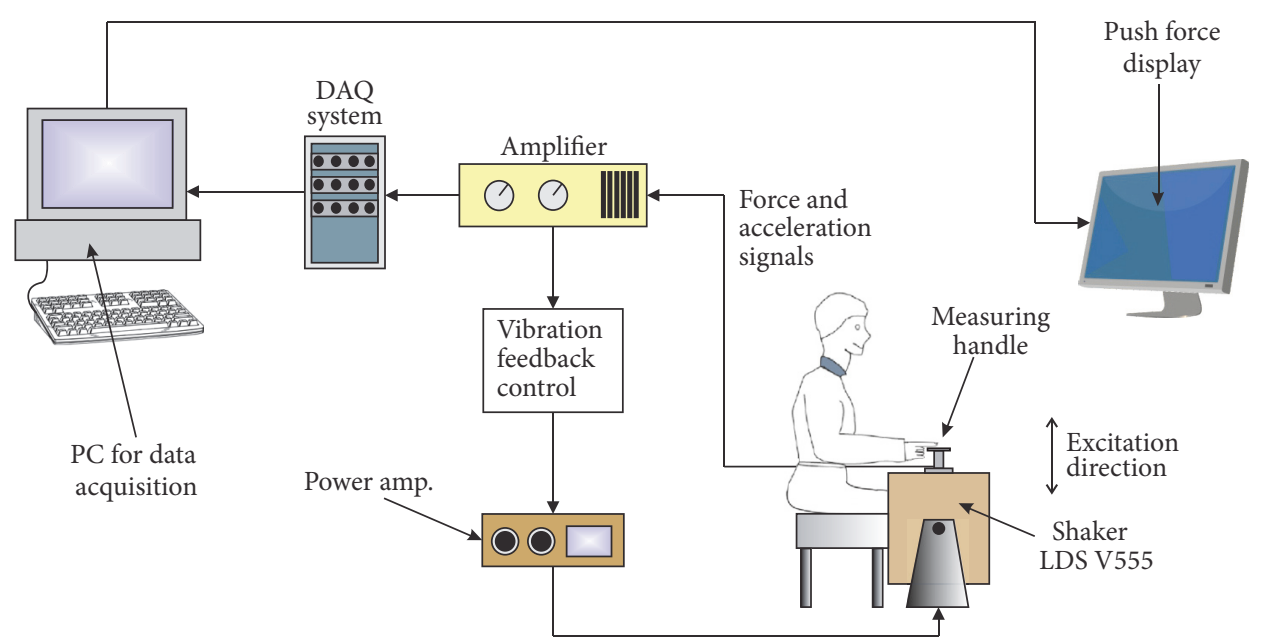

FIgURE 6: Experimental setup used in the study for the finger apparent-mass measurements.

\section{Experimental Work}

3.1. The Measuring Device. To derive the parameters for the models described above, the AM of a single finger needs to be measured (in this study, the index finger was chosen). Since the masses of an index finger are relatively small compared to the whole hand-arm system, a new device, capable of accurate single-finger measurements, needed to be developed. The general measuring principle from previous research $[9,27,28]$ was modified to reduce the number of sensors needed, thereby reducing the complexity and the mass of the measuring device. The device used in this study is shown in Figure 5 and consists of an aluminum finger-support rectangle, on the bottom side of which an accelerometer was attached using adhesive. The rectangle is screwed onto a force sensor that is attached to the top of an aluminum base. The bottom of the aluminum base is circular with a pattern of holes that are used for fixing it to an electrodynamic shaker.
The dynamic forces of the finger were measured in the direction of excitation using a Kistler force sensor type 9317B and a Kistler 5073 charge amplifier. The piezoelectric force transducer together with the Kistler 5073 charge amplifier measures both the dynamic and the quasi-static forces that are exerted on the finger-support rectangle. The dynamic component is used for the AM calculations and the quasistatic component is displayed to the operator for pushingforce adjustments during testing. To measure the acceleration of the finger, an accelerometer type PCB T333B30 was used, which was attached to the center of the finger-support rectangle, as suggested by Adewusi et al. [31].

3.2. Experimental Setup. Figure 6 illustrates the experimental setup used in this study. An electrodynamic shaker type LDS V555 was used to generate the excitation. The shaker was orientated in a vertical position and the measuring device was fixed on top of the shaker. A broadband random excitation 
from 5 to $500 \mathrm{~Hz}$ with a power spectral density (PSD) of $10\left(\mathrm{~m} \mathrm{~s}^{-2}\right)^{2} \mathrm{~Hz}^{-1}$ was used.

The measurements were done on a single operator (age: 29 years; body mass: $74 \mathrm{~kg}$; body height: $194 \mathrm{~cm}$ ). The operator was seated adjacent to the shaker and the angle of the elbow was adjusted to $90^{\circ}$. The operator held his forearm pronated and pushed down on the aluminum rectangle with his index finger. A visual feedback display was used to help the operator keep a constant pushing force of $8 \mathrm{~N}$. Three sets of measurements were conducted: one with only the distal phalanx (one-phalanx measurement), one with the middle and distal phalanxes (two-phalanx measurement), and one with the entire finger (named three-phalanx measurement) on the instrument handle. Each set was measured four times and then averaged.

A National Instruments 9234 acquisition module, the National Instruments 9178 DAQ system, and LabVIEW 2010 were used to acquire the measured data; a sampling rate of $10 \mathrm{kHz}$ was used. The raw data was then analyzed using Matlab 2012 software.

3.3. Identifying the Measured Apparent Mass. The dynamic force $\widetilde{F}(t)$ and acceleration $\widetilde{A}(t)$ signals at the finger-device interface are measured simultaneously and in the direction of excitation. The combined AM of the finger and the measuring device (denoted as total finger, $\mathrm{AM}_{\mathrm{TF}}$ ) is calculated using (3) from Section 2.1. The AM of the empty measuring device $\mathrm{AM}_{\mathrm{Dev}}$ is also calculated, and using (4), the pure AM of the finger can now be identified.

Besides the dynamic forces, the quasi-static forces were also measured during the experiment and shown in real time on a display to provide feedback to the test operator for pushing-force adjustments. To obtain the static pushing-force component $F_{\mathrm{p}}$, the measured samples are averaged in the time domain:

$$
F_{\mathrm{p}}=\operatorname{Mean}(\widetilde{F}(t))
$$

where the averaging period was $0.5 \mathrm{~s}$, to allow for quick pushing-force adjustments by the operator.

\section{Parameter Identification and Model Constraints}

With the AM of the index finger measured, the parameters for each model were determined through iterative minimization of the constrained error function. The minimization was made sequentially on all three sets of measurements: onephalanx, two-phalanx, and three-phalanx. The same general procedure as presented by Stein et al. [29] was used. First, the differences between the measured $\mathrm{AM}_{\text {mea }}$ and modeled $\mathrm{AM}_{\text {mod }} \mathrm{AM}$ were determined for each frequency $i$ :

$$
\begin{aligned}
\Delta_{i}= & \left(\operatorname{Re}\left(\mathrm{AM}_{\text {mea }_{i}}(\mathrm{j} \omega)\right)-\operatorname{Re}\left(\mathrm{AM}_{\bmod _{i}}(\mathrm{j} \omega)\right)\right)^{2} \\
& +\left(\operatorname{Im}\left(\mathrm{AM}_{\text {mea }_{i}}(\mathrm{j} \omega)\right)-\operatorname{Im}\left(\operatorname{AM}_{\text {mod }_{i}}(\mathrm{j} \omega)\right)\right)^{2},
\end{aligned}
$$

where the differences were calculated separately for the real and imaginary parts of the complex AM and squared prior to their summation. The frequency of the data used in (22) ranged from 5 to $500 \mathrm{~Hz}$ with a frequency resolution of $1 \mathrm{~Hz}$. The constrained error function was then calculated,

$$
\text { Err }=\sqrt{\frac{1}{N} \sum_{i=1}^{N} \Delta_{i}}
$$

and minimized to determine the model parameters using the Matlab 2012 fminsearch function. The fminsearch function uses the simplex search method of Lagarias et al. [32] and is a direct search method that does not use numerical or analytical gradients. Besides the error function, the $R^{2}$ value, which is often used in curve-fitting analysis, was also used to further assess how well the models fit the measured data.

Since the parameter search was done sequentially, the 1Phalanx model parameters,

$$
\begin{aligned}
& \operatorname{Par}_{1-\mathrm{Pha}}=\left[m_{\mathrm{d}}, m_{\mathrm{ds}}, m_{\mathrm{a} 1}, k_{\mathrm{d}}, k r_{\mathrm{dm}}, k_{\mathrm{dm}}, k r_{\mathrm{a} 1}, k_{\mathrm{a} 1}, c_{\mathrm{d}}, c r_{\mathrm{dm}},\right. \\
& \left.\quad c_{\mathrm{dm}}, c r_{\mathrm{a} 1}, c_{\mathrm{a} 1}\right],
\end{aligned}
$$

were determined first. The 1-Phalanx parameters were then used as the initial vector to find the missing 2-Phalanx model parameters:

$$
\begin{aligned}
& \operatorname{Par}_{2-\mathrm{Pha}}=\left[m_{\mathrm{m}}, m_{\mathrm{ms}}, m_{\mathrm{a} 2}, k_{\mathrm{m}}, k r_{\mathrm{mp}}, k_{\mathrm{mp}}, k r_{\mathrm{a} 2}, k_{\mathrm{a} 2}, c_{\mathrm{m}},\right. \\
& \left.\quad c r_{\mathrm{mp}}, c_{\mathrm{mp}}, c r_{\mathrm{a} 2}, c_{\mathrm{a} 2}\right] .
\end{aligned}
$$

The same procedure was also used to find the missing 3Phalanx model parameters:

$$
\begin{aligned}
& \operatorname{Par}_{3-\mathrm{Pha}}=\left[m_{\mathrm{p}}, m_{\mathrm{ps}}, m_{\mathrm{a} 3}, k_{\mathrm{p}}, k r_{\mathrm{pi}}, k_{\mathrm{pi}}, k r_{\mathrm{a} 3}, k_{\mathrm{a} 3}, c_{\mathrm{p}}, c r_{\mathrm{pi}}, c_{\mathrm{pi}},\right. \\
& \left.\quad c r_{\mathrm{a} 3}, c_{\mathrm{a} 3}\right] .
\end{aligned}
$$

The speed and stability of the computational algorithm and the validity of the obtained model results depend on suitable constraints for the searched model parameters [20]. Due to the lack of sufficient single-finger damping and stiffness data, it proved difficult to determine the exact damping $\left(c r_{i}, c_{i}\right)$ and stiffness $\left(k r_{i}, k_{i}\right)$ constraint ranges. The ranges were therefore left relatively broad to ensure that all possible solutions were taken into consideration. It was, however, possible to define a relatively small range for the mass parameters $m_{i}$. Each mass in the model represents an anatomical part of the index finger, for example, phalanx bones, skin, or muscle tissue, so the hand and the static masses of these parts can easily be determined using anthropometric data.

Based on the finger models' configurations, the constraints can be divided into three parts:

(i) The mass, translational, and rotational parameters that are used to model the phalanx bones and interphalanx joint stiffness and damping properties.

(ii) The mass and translational parameters representing the properties of the skin and muscle tissues.

(iii) The additional parameters, which are used to model the indirect contribution to the measured AM. It has proven difficult to experimentally determine exactly how much apparent mass is added by the fingers and the hand during measurements. 


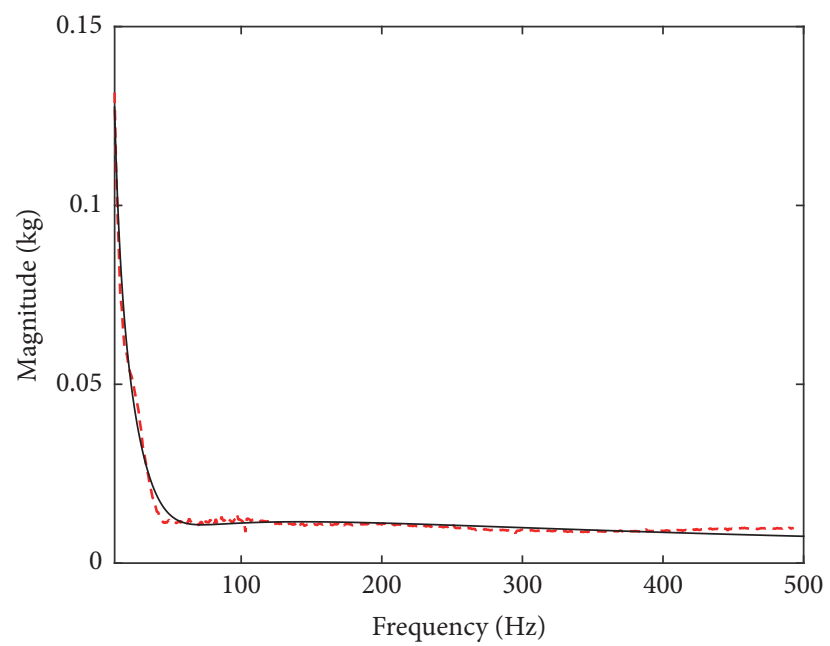

- - - Measured

- Modeled

(a)

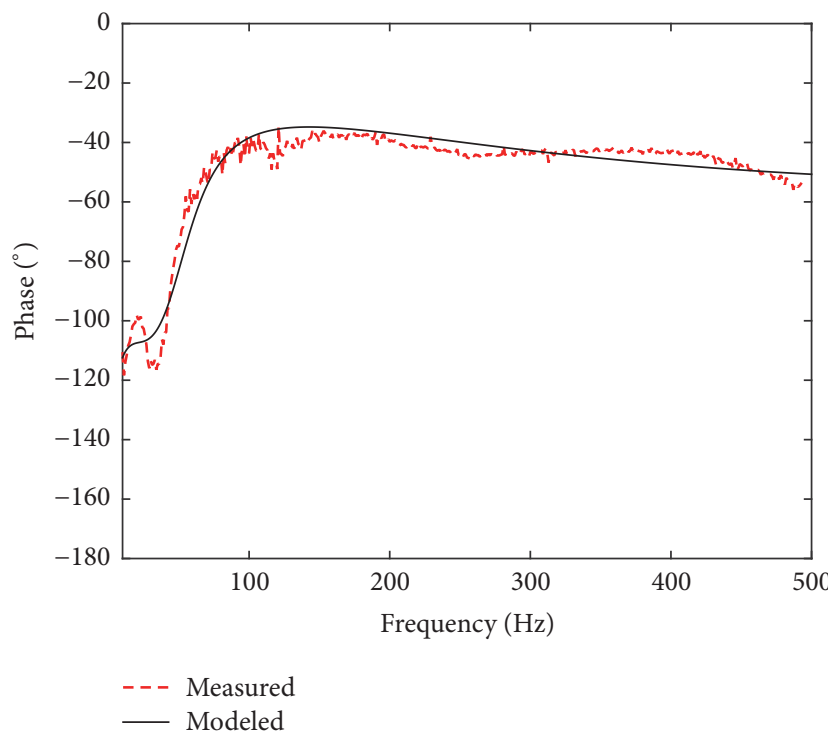

(b)

FIGURE 7: Comparison of the one-phalanx measurement and 1-Phalanx model apparent mass: (a) magnitude; (b) phase.

The constraints for all three models are presented below:

$$
\begin{aligned}
& 8 \mathrm{~g}<m_{\mathrm{d}}, m_{\mathrm{m}}, m_{\mathrm{p}}<32 \mathrm{~g} \\
& 1 \mathrm{Ns} \mathrm{m} \mathrm{rad}^{-1}<c r_{\mathrm{dm}}, c r_{\mathrm{mp}}, c r_{\mathrm{pi}} \\
& <1000 \mathrm{Ns} \mathrm{m} \mathrm{rad}^{-1} \\
& 1 \mathrm{Nm} \mathrm{rad}^{-1}<k r_{\mathrm{dm}}, k r_{\mathrm{mp}}, k r_{\mathrm{pi}}<1 e 4 \mathrm{Nm} \mathrm{rad}^{-1} \\
& 1 e-1 \mathrm{Ns} \mathrm{m}^{-1}<c_{\mathrm{dm}}, c_{\mathrm{mp}}, c_{\mathrm{pi}}<500 \mathrm{Ns} \mathrm{m}^{-1} \\
& 1 \mathrm{~N} \mathrm{~m}^{-1}<k_{\mathrm{dm}}, k_{\mathrm{mp}}, k_{\mathrm{pi}}<5 e 4 \mathrm{~N} \mathrm{~m}^{-1} \\
& 0.01 \mathrm{~g}<m_{\mathrm{ds}}, m_{\mathrm{ms}}, m_{\mathrm{ps}}<5 \mathrm{~g} \\
& 1 e-1 \mathrm{Ns} \mathrm{m}^{-1}<c_{\mathrm{d}}, c_{\mathrm{m}}, c_{\mathrm{p}}<500 \mathrm{Ns} \mathrm{m}^{-1} \\
& 1 \mathrm{~N} \mathrm{~m}^{-1}<k_{\mathrm{d}}, k_{\mathrm{m}}, k_{\mathrm{p}}<5 e 4 \mathrm{~N} \mathrm{~m}^{-1} \\
& 5 \mathrm{~g}<m_{\mathrm{a} 1}, m_{\mathrm{a} 2}, m_{\mathrm{a} 3}<250 \mathrm{~g} \\
& 1 e-3 \mathrm{Ns} \mathrm{m} \mathrm{rad}^{-1}<\mathrm{cr}_{\mathrm{a} 1}, c r_{\mathrm{a} 2}, c r_{\mathrm{a} 3}<500 \mathrm{Ns} \mathrm{m} \mathrm{rad}^{-1} \\
& 1 \mathrm{Nm} \mathrm{rad}^{-1}<k r_{\mathrm{a} 1}, k r_{\mathrm{a} 2}, k r_{\mathrm{a} 3}<5 e 4 \mathrm{Nm} \mathrm{rad}^{-1} \\
& 1 e-1 \mathrm{Ns} \mathrm{m}^{-1}<c_{\mathrm{a} 1}, c_{\mathrm{a} 2}, c_{\mathrm{a} 3}<500 \mathrm{Ns} \mathrm{m}^{-1} \\
& 1 e-1 \mathrm{Nm}^{-1}<k_{\mathrm{a} 1}, k_{\mathrm{a} 2}, k_{\mathrm{a} 3}<5 e 4 \mathrm{~N} \mathrm{~m}^{-1} \text {. }
\end{aligned}
$$

\section{Results and Discussion}

The comparisons between the measured index-finger responses (designated "Measured") and the model-obtained responses (designated "Modeled") are shown in Figures 7-9. All three figures present the AM magnitude and phases
TABLE 1: The $R^{2}$ values, model undamped natural frequencies, and the lengths of the different elements in each model. The lengths were determined prior to the data fitting from anthropometric data.

\begin{tabular}{lcccc}
\hline Parameter & Unit & 1-Phalanx & 2-Phalanx & 3-Phalanx \\
\hline$R^{2}$ & $/$ & 0.936 & 0.943 & 0.984 \\
\hline$f_{1}$ & & 49 & 40 & 30 \\
$f_{2}$ & $\mathrm{~Hz}$ & 359 & 425 & 209 \\
$f_{3}$ & & 1072 & 591 & 437 \\
\hline$l_{\mathrm{d}}$ & 25 & 25 & 25 \\
$l_{\mathrm{ds}}$ & & 25 & 25 & 25 \\
$l_{\mathrm{m}}$ & & $/$ & 25 & 25 \\
$l_{\mathrm{ms}}$ & & $/$ & 25 & 25 \\
$l_{\mathrm{p}}$ & $\mathrm{mm}$ & $/$ & $/$ & 35 \\
$l_{\mathrm{ps}}$ & & $/$ & $/$ & 35 \\
$l_{\mathrm{a} 1}$ & & 30 & $/$ & $/$ \\
$l_{\mathrm{a} 2}$ & & $/$ & 30 & $/$ \\
$l_{\mathrm{a} 3}$ & & $/$ & $/$ & 80 \\
\hline
\end{tabular}

for different sets of measurements (one-, two-, and threephalanx) and their equivalent models (1-Phalanx, 2-Phalanx, and 3-Phalanx). As can be seen, the model-obtained results correctly simulate the measured data both for the amplitude and for the phase, and the goodness of fit improves as more phalanxes are modeled.

The agreement between the model-predicted results and the measured data is more properly rated in terms of the statistical $R^{2}$ values, which are listed in Table 1 . The $R^{2}$ values for the 1-Phalanx, 2-Phalanx, and 3-Phalanx models are 0.936, 0.943 , and 0.984 , respectively, and confirm that the models fit the measured data well. The $R^{2}$ value keeps rising as more phalanxes are added to the finger model, which suggests that the goodness of fit is improving. The phase of the models, for 


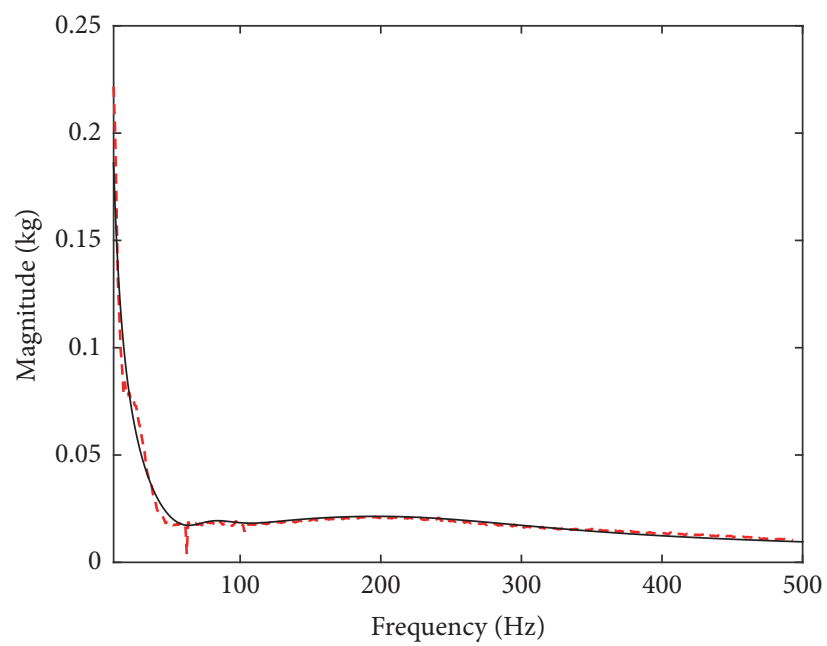

- - - Measured

- Modeled

(a)

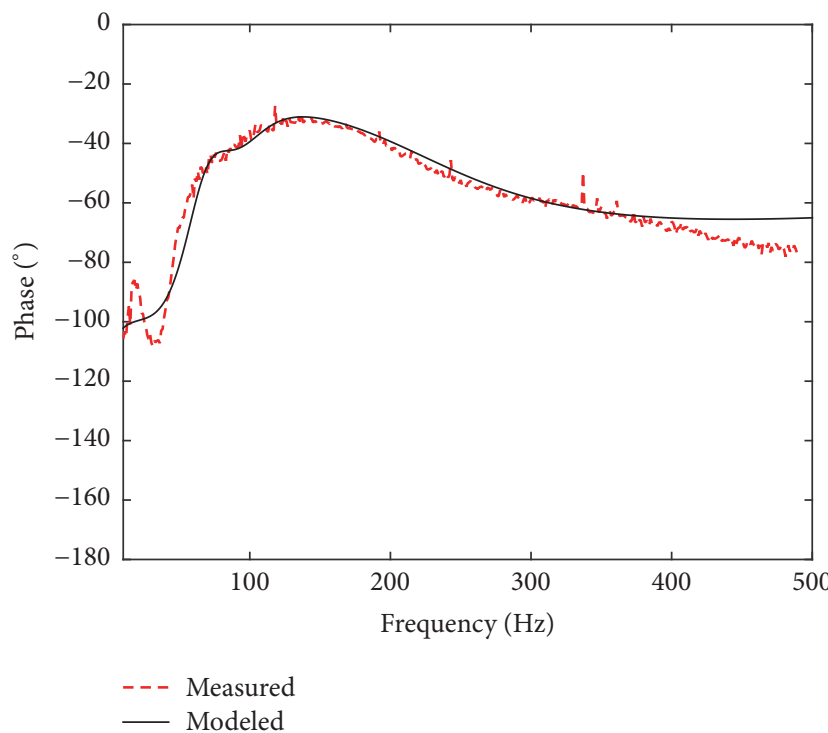

(b)

FIgURE 8: Comparison of the two-phalanx measurement and 2-Phalanx model apparent mass: (a) magnitude; (b) phase.

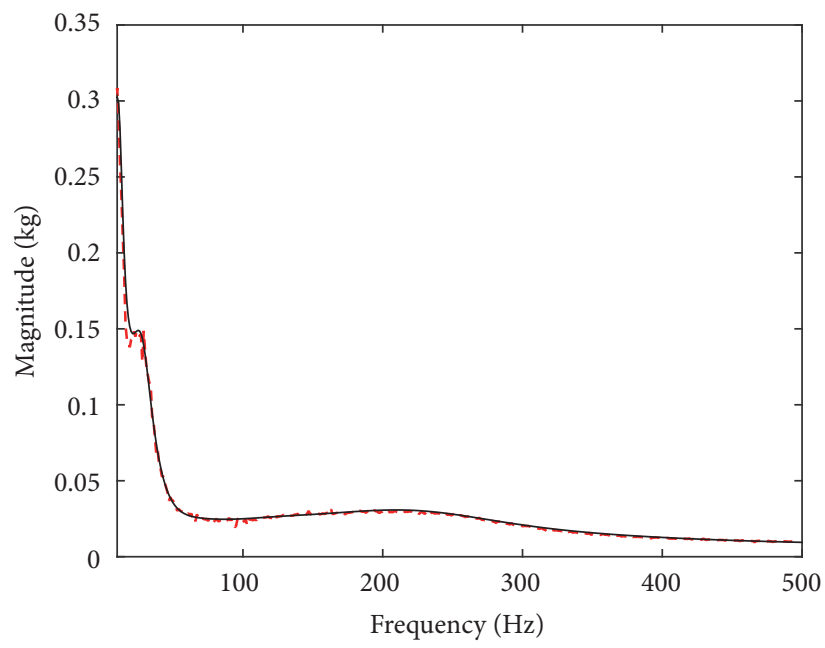

- - - Measured

- Modeled

(a)

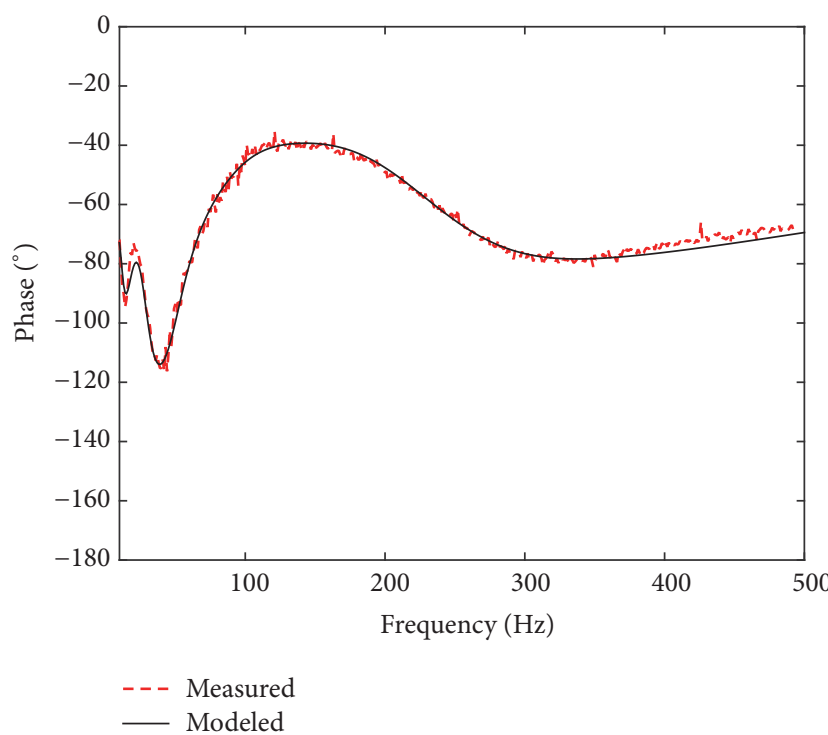

(b)

FIgURE 9: Comparison of the three-phalanx measurement and 3-Phalanx model apparent mass: (a) magnitude; (b) phase.

example, exhibits only a small discrepancy from 5 to $20 \mathrm{~Hz}$ and the 3-Phalanx model provides the best simulation for the measured data. The improvements in the trend and fit are even more evident for the magnitude, as can be seen in Figure 10, where the scale is adjusted to show the details of the graphs at higher frequencies.

Although the 3-Phalanx model, which represents the whole finger, fits the measured data well, discrepancies in both the magnitude and the phase can still be observed at frequencies below $15 \mathrm{~Hz}$. There are several possible reasons for these discrepancies: (i) There are difficulties with accurate added-mass modeling. The added AM is indirectly measured by the measuring device and is modeled using an additional lumped-mass element that changes values in each model. The influence of the added AM can also be seen in the relatively high values of the AM magnitude in the lower frequencies (up to $0.25 \mathrm{~kg}$ below $10 \mathrm{~Hz}$ ).

(ii) The lumped-element representation of the viscoelastic properties of the tissues and joints is only an approximation of the actual detailed anatomy of the index finger. 

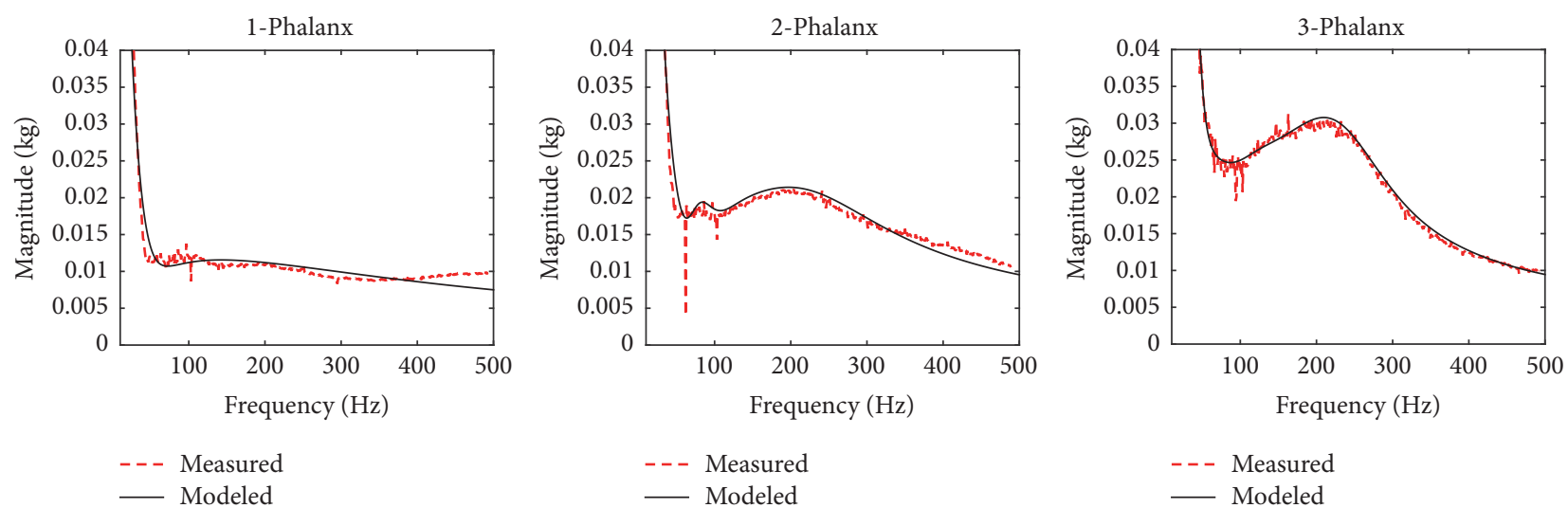

FIGURE 10: Detailed comparisons of the modeled and measured AM magnitude for all three finger phalanxes.

(iii) An equal distribution of the measured dynamic force on the model's translational mass elements is hypothesized. The actual distribution of the force may vary from phalanx to phalanx, but the current measuring device can only measure the sum force exerted by the finger.

The frequency range from 10 to $500 \mathrm{~Hz}$ is especially important for the biodynamic finger models since it represents the operational range of the majority of handheld tools [33]. These tools are a major source of vibration and frequent exposure can lead to occurrences of white-fingers syndrome. It is evident from Table 1 that at least two undamped natural frequencies for all three models lie in the $10-500 \mathrm{~Hz}$ range. This suggests that the index-finger model is also applicable for white-fingers syndrome studies.

The mass, damping, and stiffness parameters identified through the data fitting for each of the models are listed in Table 2 .

The masses of the phalanxes, which were calculated sequentially for all three models, have reasonable values compared to the static masses of the fingers (e.g., the sum mass of the index finger is $63.78 \mathrm{~g}$ ). The hand accounts for $0.66 \%$ of the total body mass [34], which is $488 \mathrm{~g}$ for the operator in this study, and the index finger therefore represents $13.1 \%$ of the total hand mass. The masses of the skin in contact with the measuring device range from 0.1 to $4 \mathrm{~g}$, which suggests that only a small portion of the phalanx tissue is in rigid contact with the measuring device. A direct comparison with other research proved difficult due to the lack of detailed finger data, but the ranges of the stiffness and damping were analyzed. The translational stiffness values are lower in comparison with those obtained by other researchers (e.g., $[3,19,20]$ ), and the damping is also lower for the distal and middle phalanx and comparable for the proximal phalanx. The reason for different value ranges is mainly due to the scale of the finger-measurements data that were used for the modeling. While other researchers measured the biodynamic responses of all five fingers combined on their instrument handles, this study focused on measurements made on a single finger at a lower pushing force.
As was expected from the measurements, the parameters used to model the added AM, that is, $m_{\mathrm{ai}}, c r_{\mathrm{ai}}, c_{\mathrm{ai}}, k_{\mathrm{ai}}$, and $k r_{\text {ai }}$, varied with each model since a different part of the finger/hand is indirectly measured and added to the finger's AM. The damping and stiffness values obtained from previous models change as more phalanxes are added, but the changes can be viewed as a convergence process to the appropriate final values of the whole finger. The middle phalanx exhibits a considerable rise in both stiffness and damping, indicating that most of the force is exerted on the measuring device via this phalanx.

Also, the purpose of this study was to develop an improved biodynamic model of an individual finger. Bearing in mind that the light skin-mass elements negligibly influence the total biodynamic response of the finger and that the added mass represents the palm influencing the finger, the effective degrees of freedom of the whole-finger model (3Phalanx) are only six ( $Y$-direction lateral and rotational at the interphalangeal joints). The model, however, still provides a reasonable simulation of the basic biodynamic features of the index finger and can therefore be useful for research on white-fingers syndrome and also for the development of antivibration protection.

\section{Conclusions}

A novel, sequential approach to biodynamic finger modeling is proposed in this study. Three mechanical models of the index finger were developed and the model parameters were obtained by minimizing the error function between the modeled AM and the measured AM. The required AM data was measured with a newly developed instrument handle capable of accurate, single-finger measurements. Since the measuring device measures only one point (single coupling), the approach to modeling was sequential: first, the onephalanx measurements were used to obtain the 1-Phalanx model (representing the distal phalanx) parameters. The calculated parameters were then used as an initial vector in the 2-Phalanx finger model, which produced the second set of parameters. Those were in turn used for the whole-finger (3-Phalanx) parameter search. The presented procedure establishes a systematic bottom-up approach to 
TABLE 2: Parameters of the biodynamic response-based models determined from the index-finger measurements using data fitting.

\begin{tabular}{|c|c|c|c|c|}
\hline Parameter & Unit & 1-Phalanx & 2-Phalanx & 3-Phalanx \\
\hline$m_{\mathrm{d}}$ & \multirow{9}{*}{ g } & 13.297 & 10.457 & 20.016 \\
\hline$m_{\mathrm{ds}}$ & & 1.542 & 1.040 & 3.893 \\
\hline$m_{\mathrm{m}}$ & & / & 16.906 & 14.887 \\
\hline$m_{\mathrm{ms}}$ & & I & 2.998 & 0.690 \\
\hline$m_{\mathrm{p}}$ & & I & 1 & 24.189 \\
\hline$m_{\mathrm{ps}}$ & & I & I & 0.109 \\
\hline$m_{\mathrm{a} 1}$ & & 56.364 & I & I \\
\hline$m_{\mathrm{a} 2}$ & & I & 33.060 & I \\
\hline$m_{\mathrm{a} 3}$ & & 1 & 1 & 237.11 \\
\hline$c r_{\mathrm{dm}}$ & \multirow{6}{*}{ Ns $m \operatorname{rad}^{-1}$} & 104.187 & 127.29 & 110.29 \\
\hline$c r_{\mathrm{mp}}$ & & I & 387.29 & 437.25 \\
\hline$c r_{\mathrm{pi}}$ & & I & I & 113.74 \\
\hline$c r_{\mathrm{a} 1}$ & & 80.596 & I & I \\
\hline$c r_{\mathrm{a} 2}$ & & I & 352.78 & I \\
\hline$c r_{\mathrm{a} 3}$ & & 1 & 1 & 74.371 \\
\hline$c_{\mathrm{dm}}$ & \multirow{6}{*}{$\mathrm{Ns} \mathrm{m}^{-1}$} & 3.370 & 1.504 & 8.563 \\
\hline$c_{\mathrm{mp}}$ & & I & 4.422 & 0.344 \\
\hline$c_{\mathrm{pi}}$ & & I & I & 104.245 \\
\hline$c_{\mathrm{a} 1}$ & & 11.783 & I & I \\
\hline$c_{\mathrm{a} 2}$ & & I & 13.398 & I \\
\hline$c_{\mathrm{a} 3}$ & & 1 & 1 & 11.159 \\
\hline$c_{\mathrm{d}}$ & \multirow{3}{*}{$\mathrm{Ns} \mathrm{m}^{-1}$} & 24.959 & 8.654 & 7.992 \\
\hline$c_{\mathrm{m}}$ & & 1 & 15.605 & 14.624 \\
\hline$c_{\mathrm{p}}$ & & I & 1 & 0.132 \\
\hline$k r_{\mathrm{dm}}$ & \multirow{6}{*}{$\mathrm{Nm} \mathrm{rad}^{-1}$} & 1140.17 & 781.68 & 1437.15 \\
\hline$k r_{\mathrm{mp}}$ & & I & 3034.21 & 2813.91 \\
\hline$k r_{\mathrm{pi}}$ & & I & I & 6037.17 \\
\hline$k r_{\mathrm{al}}$ & & 7782.91 & I & I \\
\hline$k r_{\mathrm{a} 2}$ & & I & 14886.29 & I \\
\hline$k r_{\mathrm{a} 3}$ & & 1 & 1 & 14740.55 \\
\hline$k_{\mathrm{dm}}$ & \multirow{6}{*}{$\mathrm{N} \mathrm{m}^{-1}$} & 1527.32 & 2089.43 & 2509.88 \\
\hline$k_{\mathrm{mp}}$ & & I & 4852.53 & 6419.53 \\
\hline$k_{\mathrm{pi}}$ & & I & I & 3518.45 \\
\hline$k_{\mathrm{a} 1}$ & & 177.00 & I & I \\
\hline$k_{\mathrm{a} 2}$ & & I & 106.11 & I \\
\hline$k_{\mathrm{a} 3}$ & & 1 & 1 & 285.47 \\
\hline$k_{\mathrm{d}}$ & \multirow{3}{*}{$\mathrm{N} \mathrm{m}^{-1}$} & 1570.12 & 1227.23 & 981.13 \\
\hline$k_{\mathrm{m}}$ & & I & 23906.07 & 33889.44 \\
\hline$k_{\mathrm{p}}$ & & 1 & 1 & 469.11 \\
\hline
\end{tabular}

biodynamic modeling, which can also be used to develop a detailed model of the complex hand-arm system. Examining the results, very good agreement was achieved between the measured and simulated data and an improved fit can be observed as more phalanxes are added to the model.

\section{Conflicts of Interest}

The authors declare that there are no conflicts of interest regarding the publication of this paper.

\section{References}

[1] M. J. Griffin, Handbook of Human Vibration, Academic Press, London, UK, 1990.

[2] M. Bovenzi, "Exposure-response relationship in the hand-arm vibration syndrome: An overview of current epidemiology research," International Archives of Occupational and Environmental Health, vol. 71, no. 8, pp. 509-519, 1998.

[3] R. G. Dong, J. Z. Wu, and D. E. Welcome, "Recent advances in biodynamics of human hand-arm system," Industrial Health, vol. 43, no. 3, pp. 449-471, 2005. 
[4] J. Z. Wu, K. Krajnak, D. E. Welcome, and R. G. Dong, "Analysis of the dynamic strains in a fingertip exposed to vibrations: Correlation to the mechanical stimuli on mechanoreceptors," Journal of Biomechanics, vol. 39, no. 13, pp. 2445-2456, 2006.

[5] R. G. Dong, D. E. Welcome, T. W. McDowell, and J. Z. Wu, "Measurement of biodynamic response of human hand-arm system," Journal of Sound and Vibration, vol. 294, no. 4, pp. 807827, 2006.

[6] ISO-10819, Mechanical Vibration and Shock- Hand-Arm Vibration-Method for the Measurement and Evalutation of the Vibration Transmissibility of Gloves at the Palm of the Hand, International Organization for Standardization, Geneva, Switzerland, 1996.

[7] R. G. Dong, S. Rakheja, T. W. McDowell et al., "A method for assessing the effectiveness of anti-vibration gloves using biodynamic responses of the hand-arm system," Journal of Sound and Vibration, vol. 282, no. 3-5, pp. 1101-1118, 2005.

[8] N. Shibata, N. Hosoya, and S. Maeda, "Establishment of oneaxis vibration test system for measurement of biodynamic response of human hand-arm system," Industrial Health, vol. 46, no. 6, pp. 629-634, 2008.

[9] L. Knez, J. Slavic, and M. Boltear, "Vibration transmissibilities of the human hand arm system exposed to Zh- and Yh- axes vibration," in Proceedings of the Kuhljevi Dnevi Conference, pp. 97-104, 2011.

[10] L. Knez, J. Slavič, and M. Boltežar, "A multi-axis biodynamic measuring handle for a human hand-arm system," Strojniski Vestnik/Journal of Mechanical Engineering, vol. 59, no. 2, pp. 7180, 2013.

[11] R. G. Dong, D. E. Welcome, X. S. Xu et al., "Mechanical impedances distributed at the fingers and palm of the human hand in three orthogonal directions," Journal of Sound and Vibration, vol. 331, no. 5, pp. 1191-1206, 2012.

[12] S. A. Adewusi, S. Rakheja, P. Marcotte, and J. Boutin, "Vibration transmissibility characteristics of the human hand-arm system under different postures, hand forces and excitation levels," Journal of Sound and Vibration, vol. 329, no. 14, pp. 2953-2971, 2010.

[13] Y. Aldien, P. Marcotte, S. Rakheja, and P.-E. Boileau, "Influence of hand-arm posture on biodynamic response of the human hand-arm exposed to zh-axis vibration," International Journal of Industrial Ergonomics, vol. 36, no. 1, pp. 45-59, 2006.

[14] P. Marcotte, Y. Aldien, P.-É. Boileau, S. Rakheja, and J. Boutin, "Effect of handle size and hand-handle contact force on the biodynamic response of the hand-arm system under zh-axis vibration," Journal of Sound and Vibration, vol. 283, no. 3-5, pp. 1071-1091, 2005.

[15] R. G. Dong, S. Rakheja, A. W. Schopper, B. Han, and W. P. Smutz, "Hand-transmitted vibration and biodynamic response of the human hand-arm: a critical review," Critical Reviews in Biomedical Engineering, vol. 29, no. 4, pp. 393-439, 2001.

[16] S. Rakheja, J. Z. Wu, R. G. Dong, A. W. Schopper, and P.É. Boileau, "Comparison of biodynamic models of the human hand-arm system for applications to hand-held power tools," Journal of Sound and Vibration, vol. 249, no. 1, pp. 55-82, 2002.

[17] S. Adewusi, S. Rakheja, and P. Marcotte, "Biomechanical models of the human hand-arm to simulate distributed biodynamic responses for different postures," International Journal of Industrial Ergonomics, vol. 42, no. 2, pp. 249-260, 2012.

[18] R. G. Dong, S. Rakheja, T. W. McDowell, D. E. Welcome, and J. $\mathrm{Z}$. Wu, "Estimation of the biodynamic responses distributed at fingers and palm based on the total response of the hand-arm system," International Journal of Industrial Ergonomics, vol. 40, no. 4, pp. 425-436, 2010.

[19] R. G. Dong, J. H. Dong, J. Z. Wu, and S. Rakheja, "Modeling of biodynamic responses distributed at the fingers and the palm of the human hand-arm system," Journal of Biomechanics, vol. 40, no. 10, pp. 2335-2340, 2007.

[20] R. G. Dong, D. E. Welcome, T. W. McDowell, and J. Z. Wu, "Modeling of the biodynamic responses distributed at the fingers and palm of the hand in three orthogonal directions," Journal of Sound and Vibration, vol. 332, no. 4, pp. 1125-1140, 2013.

[21] D. T. V. Pawluk and R. D. Howe, "Dynamic lumped element response of the human fingerpad," Journal of Biomechanical Engineering, vol. 121, no. 2, pp. 178-183, 1999.

[22] D. L. Jindrich, Y. Zhou, T. Becker, and J. T. Dennerlein, "Non-linear viscoelastic models predict fingertip pulp forcedisplacement characteristics during voluntary tapping," Journal of Biomechanics, vol. 36, no. 4, pp. 497-503, 2003.

[23] M. A. Srinivasan, "Surface deflection of primate fingertip under line load," Journal of Biomechanics, vol. 22, no. 4, pp. 343-349, 1989.

[24] E. R. Serina, E. Mockensturm, C. D. Mote Jr., and D. Rempel, "A structural model of the forced compression of the fingertip pulp," Journal of Biomechanics, vol. 31, no. 7, pp. 639-646, 1998.

[25] J. Z. Wu, R. G. Dong, S. Rakheja, A. W. Schopper, and W. P. Smutz, "A structural fingertip model for simulating of the biomechanics of tactile sensation," Medical Engineering Physics, vol. 26, pp. 165-175, 2004.

[26] J. Z. Wu, R. G. Dong, C. M. Warren, D. E. Welcome, and T. W. McDowell, "Analysis of the effects of surface stiffness on the contact interaction between a finger and a cylindrical handle using a three-dimensional hybrid model," Medical Engineering Physics, vol. 36, pp. 831-841, 2014.

[27] E. Concettoni and M. Griffin, "The apparent mass and mechanical impedance of the hand and the transmission of vibration to the fingers, hand, and arm," Journal of Sound and Vibration, vol. 325, no. 3, pp. 664-678, 2009.

[28] J. Z. Wu, R. G. Dong, W. P. Smutz, and S. Rakheja, "Dynamic interaction between a fingerpad and a flat surface: experiments and analysis," Medical Engineering Physics, vol. 25, pp. 397-406, 2003.

[29] G. J. Stein, P. Múčka, B. Hinz, and R. Blüthner, "Measurement and modelling of the $y$-direction apparent mass of sitting human body-cushioned seat system," Journal of Sound and Vibration, vol. 322, no. 1-2, pp. 454-474, 2009.

[30] A. A. Shabana, Computational Dynamics, Wiley, West Sussex, UK, 3rd edition, 2010.

[31] S. A. Adewusi, S. Rakheja, P. Marcotte, and P.-E. Boileau, "On the discrepancies in the reported human hand-arm impedance at higher frequencies," International Journal of Industrial Ergonomics, vol. 38, no. 9-10, pp. 703-714, 2008.

[32] J. C. Lagarias, J. A. Reeds, M. . Wright, and P. E. Wright, "Convergence properties of the Nelder-Mead simplex method in low dimensions," SIAM Journal on Optimization, vol. 9, no. 1, pp. 112-147, 1999.

[33] M. J. Griffin, "Measurement, evaluation, and assessment of occupational exposures to hand-transmitted vibration," Occupational and Environmental Medicine, vol. 54, no. 2, pp. 73-89, 1997.

[34] A. Tözeren, Human Body Dynamics: Classical Mechanics and Human Movement, Springer, New York, NY, USA, 2000. 


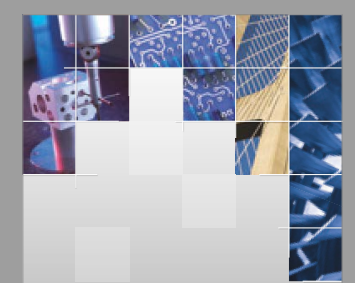

\section{Enfincering}
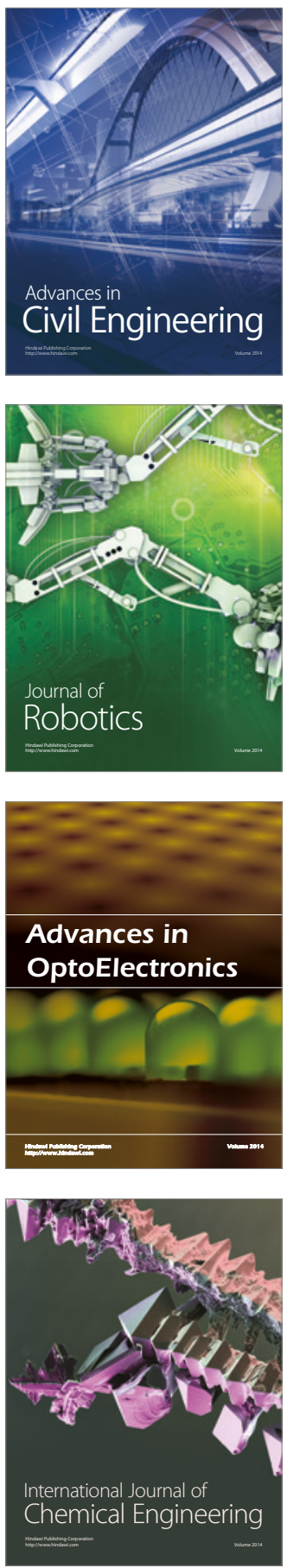

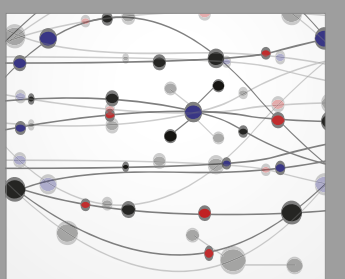

The Scientific World Journal

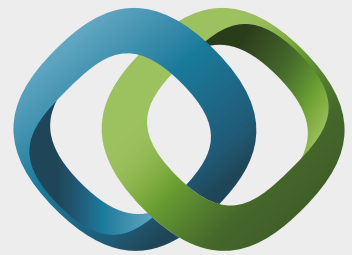

\section{Hindawi}

Submit your manuscripts at

https://www.hindawi.com
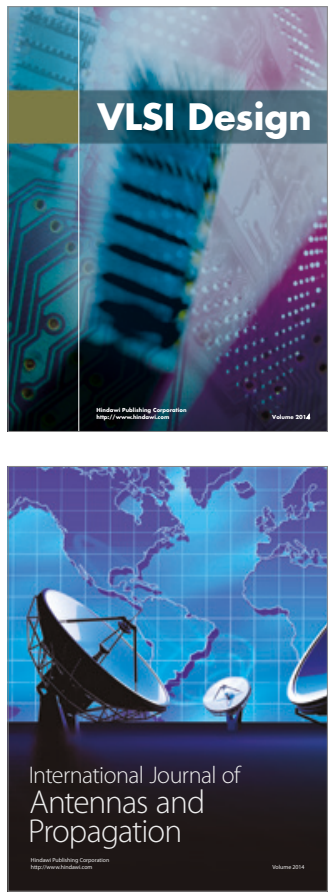

\section{Rotating}

Machinery
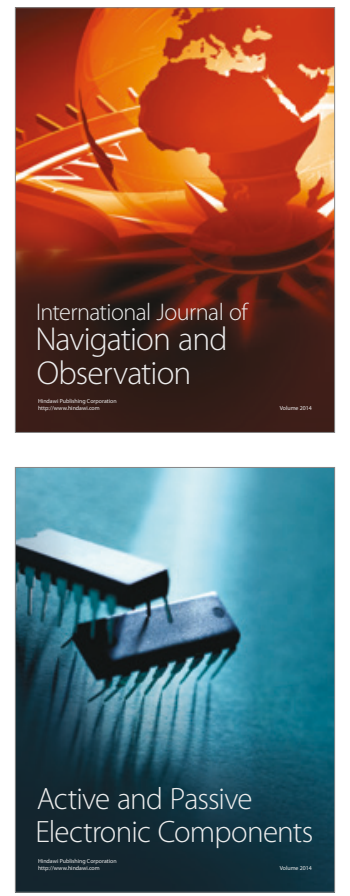
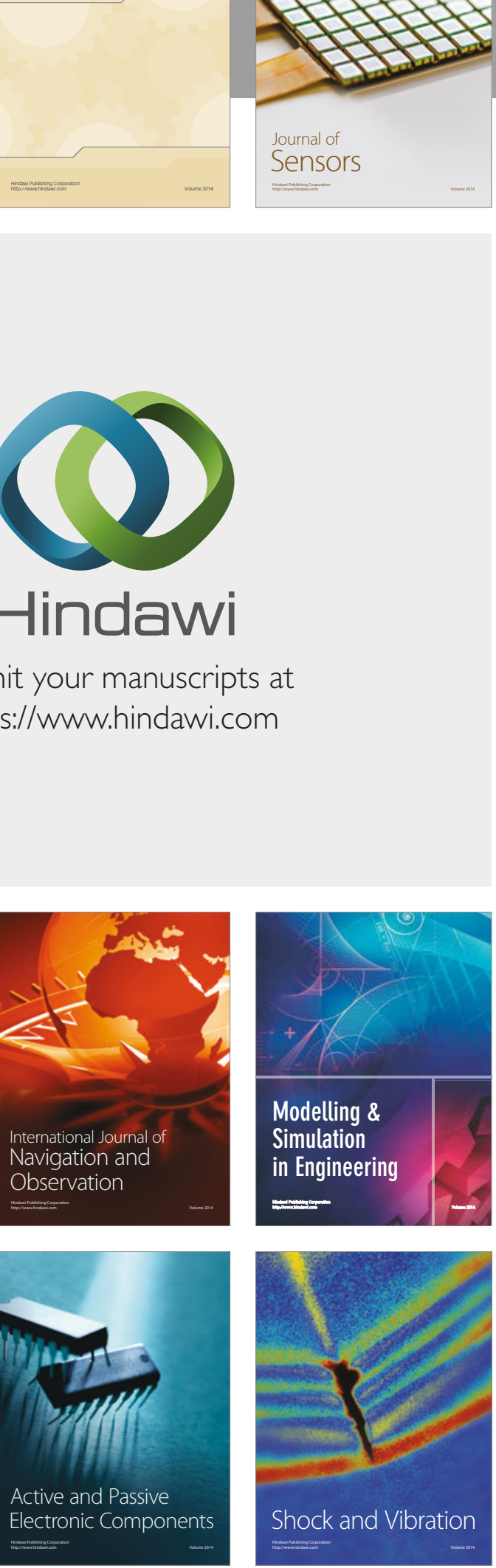
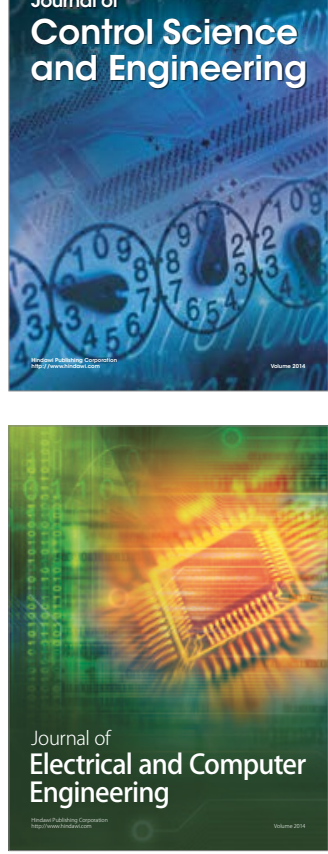

Distributed

Journal of

Control Science

and Engineering
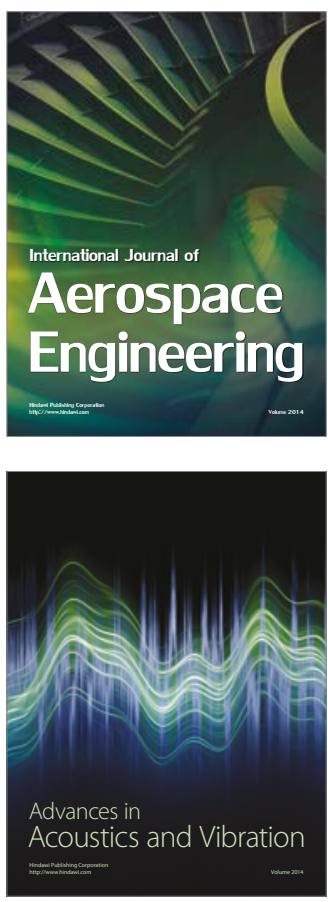

Sensor Networks 